\title{
Green Materials: Referees 2019
}

The following is a list of referees who have reviewed papers for Green Materials between 1 January 2019 and 31 December 2019. The Institution of Civil Engineers is very grateful for their assistance.

We are continually looking for suitable reviewers for papers submitted to Green Materials. Papers published in ICE Science journals must be submitted to at least two independent referees to judge accuracy, style, impact, importance and interest.

Varenyam Achal

Noor Afifah Ahmad

Miguel Aldas

Mateusz Barczewski

Mehul Barde

Kathryn Beers

Fabrice Burel

Marian Butu

Ziyi Chai

Felipe Cicaroni Fernandes

Gurjot Dhaliwal

\author{
Laura Dubrulle \\ Sami El Awad Azrak \\ Yunli Fang \\ Pedro Fonte \\ Étienne Grau \\ Jaime Grunlan \\ Huizhang Guo \\ Amine Harrane \\ Mohammad L. Hassan \\ A. Richard Horrocks \\ Ghanim Kashwani
}

If you are interested in reviewing articles on any topic related to green materials, please submit your name, qualifications or $\mathrm{CV}$, and areas of expertise. We are in need of individuals who will agree to review papers in a timely fashion (within 3 to 4 weeks of receipt) and provide confidential feedback to the Editorial Advisory Panel concerning the quality of the paper and any suggested revisions that would be appropriate.

If you are such a person, please contact Rebecca Rivers (tel.: +44 (0)207 665 2241; e-mail: rebecca.rivers@ice.org.uk) for more information on the referee process

Suresh Kattimuttathu
Turgay Korkut
Vijay Kumar Thakur
Gerard Lligadas
Yuri Lvov
Jyothi M. S.
Alex Morgan
Kevin Nagy
Sasan Nouranian
Peter Olsén
Art Ragauskas

Carla Silva

Rodolphe Sonnier Emma Strömberg John Summerscales Mehdi Tajvidi Bhausaheb Tawade Chad Ulven Prakash Wadgaonkar Haibo Wang Jeremiah Woodcock 